Article

\title{
Artificial Intelligence Systems-Aided News and Copyright: Assessing Legal Implications for Journalism Practices
}

\author{
Javier Díaz-Noci ${ }^{(D)}$ \\ Communication Departament, Pompeu Fabra University, 08018 Barcelona, Spain; javier.diaz@upf.edu; \\ Tel.: +34-93-542-1220
}

Received: 29 March 2020; Accepted: 6 May 2020; Published: 8 May 2020

\begin{abstract}
Automated news, or artificial intelligence systems (AIS)-aided production of news items, has been developed from 2010 onwards. It comprises a variety of practices in which the use of data, software and human intervention is involved in diverse degrees. This can affect the application of intellectual property and copyright law in many ways. Using comparative legal methods, we examine the implications of them for some legal categories, such as authorship (and hence required originality) and types of works, namely collaborative, derivative and, most especially, collective works. Sui generis and neighboring rights are also considered for examination as being appliable to AIS-aided news outputs. Our main conclusion is that the economics intellectual property rights are guaranteed in any case through collective works. We propose a shorter term of duration before entering public domain. Still, there is a place for more authorial, personal rights. It shows, however, more difficulty when coming to moral rights, especially in Common Law countries.
\end{abstract}

Keywords: automated news; intellectual property; copyright law

\section{Introduction}

In recent times, the automated production of news items has joined the traditional human-only creation of information. It has adopted many forms, at least from 2014 and 2015. This has been called algorithm journalism [1,2] or robot journalism, but, in general terms, it is mentioned as automated journalism $[3,4]$, and it is the type of news item created with the aid of autonomous intelligent systems (AIS) [5-7]. The technology "shall eventually lead to autonomous technology that can perceive, learn, decide and create without any human intervention" [8]. The question of a gradual (even if partial, at least for now) substitution of human by machines is in the background. The generation of new professional skills and profiles is a trend, as well, that will continue in the coming years, as stated, for instance, by [9].

This is clearly beyond the traditional use of some tools to produce copyrightable works, for instance, photography [8] (p. 321) or word processors. To the extent journalists and the media use software to help human to produce news, this is to be considered a protectable work. When machines are able to produce news for themselves, with no human help—except for the design of the software itself-then we are dealing with a different question. This kind of tool, which most likely will be improved in the near future, poses some questions on intellectual property, which is the topic of this paper.

Intellectual creation is a human activity in which we must include the varied forms of journalistic works, from simple news to more elaborated features and articles. These fall within the works protected by copyright and, in general terms, intellectual property law. We have to make an important clarification of the terms to be used relating to intellectual property. While in the Common Law legal tradition, it means copyright (which is called by legal doctrine in the other great legal tradition of 
the world, the so-called Civil Law tradition, authors' rights) and designs, patents and trademarks, in the Civil Law tradition, however, intellectual property is almost synonymous to copyright-authors' right law, and the rest is considered as being included within the industrial property denomination. This may add some difficulty when comparing both legal traditions from a transnational perspective, but it may, on the other hand, help in distinguishing the many implications of the arrival of the different outputs produced using artificial intelligence on news reporting.

We have mentioned this aspect in some previous works [10] altogether with some other issues of copyright law applied to the media and news reporting. It is our intention to explore the specific aspects involved in automated news, or news produced with the aid of artificial intelligence. As a starting point: to the extent that some human, substantial intervention is needed before the news item is delivered to the public, copyright law may be applicable to the protection of such works. When human intervention in minimal, unnecessary or accessorial, then we are dealing with a different legal nature and protection. The degree of originality-understood as the application of intellectual human skills in order to obtain a work-is a central requirement in copyright law, and even more so in the Civil Law legal tradition, in which the author is at the very core of its conception. However, and even if some national legal systems, such as the Spanish one (Art. 5.1 of the Spanish Copyright Act, TRLPI $1 / 1996$, which states that only natural persons can be considered creators of literary, artistic or scientific works), insist in considering that the only possible author needs to be human, there are some other layers of rights appliable to other agents of intellectual creation. This is the case of the collective works, singularly important in journalism, since media outputs are considered precisely like that: a collection of works commissioned to (usually hired) journalists offered to the public as a bunch produced under the investment and coordination of a corporate entity, instead of a natural person. Those corporate entities have several rights under copyright law, and ultimately they have fought, and gained to a great extent, a legal battle in the European Union to get an exclusive exploitation right to confront the great news aggregators, like Google News [11].

\section{What is Automated Journalism? A Typology of AIS-Aided Created News}

The already short development of AIS-aided, or automated news, appears, generally speaking, as a practice of presenting or producing news items out of previously gathered and structured data, normally using templates and applying some more or less complex algorithms. We follow in this respect the definition provided by A. Graefe in 2016: "It is the process of using software or algorithms to automatically generate news stories without human intervention-after the initial programming of the algorithm, of course. Thus, once the algorithm is developed, it allows for automating each step of the news production process, from the collection and analysis of data, to the actual creation and publication of news" [7] (p. 9).

The history of AIS-aided news production is scarcely ten years old. The (initially British, now global) newspaper The Guardian started with software in 2010 to produce some news on sport statistics and graphics, and in 2014 experimented in a similar way with Guarbot, a tool to produce news on financial information. The real effective experimentation can be traced back to 2014, when a journalist then hired by The Los Angeles Times, Ken Schwencke, designed an algorithm to produce some news on a low-intensity earthquake that happened that year, based on data from the United States Geological Survey service. One year later, the main French daily newspaper, Le Monde, used another algorithm designed by Data2Content and Syllabs companies to produce some news on election results, using numeric data as well. One year later, in 2015, a Chinese tool, Dreamwriter, was created by a videogames company, Tencent, to produce news on consumer prices that was 916 words long in just one minute, with apparently no mistakes. From then onwards, many other ones have appeared: Heliograf (used by The Washington Post since 2016), Quill, Soccerbot, Wordsmith by Automate Insights, used since 2014 by the Associated Press agency, Recount, StatsMonkey, Media Brain, Kognetics and RADAR are some of them [2]. 
RADAR is a rather interesting case. It was created in 2017 by a news agency, the Press Association, which in three months produced, using this software, more than 50,000 items. The software was developed by Urbs Media and financed with EUR 150 M by the Google Digital News Initiative Innovation Fund. It uses open access datasets on topics such as transport, education, health, crime and education, and it is able to produce several versions of every item adapted to the necessities of their clients. Behind the RADAR working flow, there was a team of six journalists who identified interesting topics and conducted the production of automated news.

Some topics and sections seem more appropriate to use AIS-aided newswriting. Finances, election results and especially sports coverage have appeared as the most widespread topics in which algorithms are used to produce news. Media have sometimes used chatbots to communicate with users, and these tools are able to write their own sentences, based on patterns and on topics and terms recognition. In 2017, the Innovation Lab of the Spanish native-digital journal El Confidencial created a software named AnaFut which creates football chronicles of the lower categories. Sport coverage also combines documentation and bots [12], in the case of BeSoccer. Most of those systems use as a primary source data provided by official institutions: the Spanish public broadcast service, Radio Televisión Española, decided in 2020 to experiment with data extracted from the Spanish Football Federation to offer short news on results of the lower leagues, "interpreting them and presenting a text in natural language, related to the selected event with no personal intervention", using HTML format and as a mere news, and not penalizing the SEO positioning of the source itself. Similar systems were used by The Washington Post to cover the Olympic Games in 2016.

Actually, according to Beckett [13], artificial intelligence systems can help journalists and the media in three phases: gathering, production and distribution. This can lead, however, to a wide variety of results and, which is our point from a legal perspective, intervention by human journalists. These results can be:

1) Mash-up news items can be produced, aggregating several previously published works. This results, using legal terminology, in derivative works which are obliged to mention the works and authors on which the new items are based. As an example, this is the case of Adrian Holovaty's mashed up infographics produced for the website Chicagocrime.org, [14,15]. Producing intelligent infographics is also the method developed by Intelygenz and Prodigioso Volcán in Spain from 2018 onwards (see http://losdelvolcan.com/grafia/web/): while the journalist creates his or her item, a machine-learning comprehension software scans the words and, relating them all, it creates some graphics with no human intervention-so it can be defined, in legal terms, as a derivative work-to complement them, so as to produce, once again using legal terms, a collaborative work.

2) Automatization of processes can help journalists to provide more context, data and even links (internal or external) to their items. It is common practice to search in the documentation service of the newsroom to find related news to be used and linked. Contextualization of news seems to be exclusive of human journalists, although interfaces and search engines can help in extracting that which is needed from massive databases [16] (p. 179).

3) Another relevant use of AIS in news production is the verification of information, automatically tracing sources and facts. One example is Truthmeter, "a tool that automatically scores the journalistic credibility of social media contributors in order to inform overall credibility assessments. The Truthmeter computes credibility scores based on data made available through the Twitter API" [17].

4) Content curation is another purpose in which AIS can help journalists in their search for scoops on relevant topics. This is one of the ways used by RADAR ('Reporters And Data And Robots'), a software system used by the British Press Association, which combines humans and machines to create localized stories at scale on topics such as "crime figures, hospital waiting times and pupil absences from school" [13] (p. 25).

5) An interesting application of AIS is the adaptation or customization of messages to different users, producing several versions-thus, and from a legal point of view, derivative works; any one of them is protectable under copyright law. The Swedish newspaper Svenska Dagbladet, for instance, 
designed a tool to create different homepages for users, measuring the number of clicks, time or permanence or preferences introduced by the user [18]. Out of our focus, but to be considered for its commercial interest, AIS can help with subscriptions, which is in 2020-until the coronavirus crisis, at least—a common movement in media industry, following models like that of the New York Times' paywalls. This is a called a "dynamic paywall", in which companies like Deep Bi are working.

6) Most usually, artificial intelligence systems-aided or automated news production is based on database exploitation and automatization of raw data using patterns, which results in what some authors have named database journalism [19] (p. 5). The results of those practices can be considered protectable by copyright laws as sui generis rights. Patterns are provided by humans; only when the system is able to learn, improve and create new patterns may a non-human authorship appear.

By now, then, artificial intelligence systems-aided journalism is reduced to factual content coverage, while in principle only humans are able to elaborate more complex and contextualized pieces. Factual content coverage using AIS is, however, appealing for media companies, because it provides "a cost-effective way to create high-quality factual content that does well in SEO terms" [20].

The key of all those systems, and the ones that could be improved in the next future, is whether they need post processing by humans or not. Some of them, like Monok or RADAR, do not seem to need it to produce simple news items, with no great context. Artificial intelligence systems are not able to generate text of complex or non-predictable nature, a hypothesis placed by Ufarte and Manfredi [21]; or, as Belz says, "with a lot of unpredictability in the output" [20].

\section{Methods}

The main method used in this paper is a legal, comparative analysis. Since, as mentioned, very few cases have been examined in court to this point, we will base our analysis more on doctrine than on jurisprudence or on an examination of specific legal provisions. Copyright acts do not deal, to our understanding, concretely with these issues, and most of these acts do not mention the automated production of intellectual works at all. In other words, if new legal problems appear because of the use of new tools and techniques, to this point no legal reform has been practiced to include some new provisions to cover specifically those situations, and so intellectual property principles as we know them are to be applied. Even though some legal reforms have mentioned artificial intelligence beyond the automated analysis of data, which is important, they seem not to cover the automated production of works, or at least they can only be applied to some steps of it. This is the case of the Directive of the European Union 2019/790, on copyright and related right in the digital single market, for instance Article 3.2., on text and data mining. As some relevant scholars have underlined, "the fact that artificial intelligence and robotics are much more than science fiction becomes apparent" on the working documents of the European Commission, but at the same times it appears that it is considered just "the next step in the development of a sustainable information society" [8] (p. 3). Alternatively, automated systems are a concern whenever they are used by platforms like Facebook or Youtube for users' identification and filtering [22] (p. 267), which has a reflection on the literal interpretation of Article 17 of the aforementioned European directive, to oblige Internet services to detect unauthorized (and usually derivative) works uploaded by users without copyright permission.

We will focus on two main legal categories related to copyright and intellectual property law. First, the question of authorship and, closely related to it, originality as a sine qua non requirement for the law to consider a work copyrightable. Second, the type of work. We have advanced some of them: the individual work, a single piece created usually by a single (human) author. A collaborative work, alternatively, is when two or more authors can create a combined piece. In this case, we can consider many cases in which AIS aids a human journalist to complete his or her work. A derivative work, in which a new one is created based on one or more previously existing works, is an increasingly widespread type of work. The derivative work can be created, in turn, by both humans or machines based on both human or machine-made pre-existing works. Finally, and this is probably the central part of our analysis, the collective work, is composed by many works gathered and structured under 
the coordination of another (natural or corporate) person. This is the case of newspaper, magazines, broadcasting services and webpages.

Since automated news are created (or transformed) with the help of both data, structured normally as a database, and software, some other categories of intellectual property rights are to be considered as well: the so-called, at least in some jurisdictions, sui generis rights, normally applicable to databases as a structure, equally created under the requirements and necessities of a corporate entity in order to produce intellectual works, and not necessarily to data themselves; and related, ancillary rights. This whole panorama means a complex superposition of layers of rights, some of which are accumulative and not mutually exclusive, to be considered in the many cases we will examine in the following sections. Even though if very few cases have been decided in court, it is expected that media organizations and practitioners of news reporting-journalists, photographers, infographics designers or even cartoonists, to mention some of them-will be facing some of these scenarios soon.

\section{Results}

The cross-examination of the aforementioned cases, which covers the most common practices of artificial intelligence systems-aided journalism to this point, their classification considering the legal axis of authorship (and originality) and typology of work, and the phase of journalistic work (gathering, production and dissemination) could help us to determine to what extent copyright law can cover these new products.

First of all, it is to be noted that all of them are produced due to the initiative and investment of a company, a corporate entity which is typically considered the one under whose coordination a collective work is made. This is to say that media companies as corporate entities are the producers of a collective work, not the authors of it. This is a characteristic more relevant in Civil Law countries than in the Common Law legal tradition, in which an entrepreneurial point of view is more explicit than in the most authorial, based on the creativity of individuals, approach of Civil Law countries. This, which was in the origin of copyright and authors' rights legal systems, has been modulated over time, and the importance of producers is evident in the case of, e.g., the audiovisual work. There are some movements to extend this consideration to the producers of multimedia works. One of those movements is the aforementioned lobbying activity of the major newspaper companies in Europe or the European Union to enact an ancillary exploitation right for press publishers, materialized in Article 15 of the Directive on Copyright and Related Rights in the Digital Single Market, 2019, to be implemented by state members (as of mid-2020, the only one to do so was France). Article 15 is intended to protect press publications "concerning online uses", for two years after publication. The duration of rights is notably shorter than the protection given to personal creations (all the authors' life term plus 70 years after his or her death), but is perfectly suitable for automated creations. There is an advantage in such artificial intelligence systems-aided works, since, when an author's name is not mentioned, no one has to receive "an appropriate share of the revenues". The Resolution of the 2019 AIPPI World Congress on Copyright in artificially generated work, one of the most developed documents on this area, agrees with this conception, and considers that "the term should be shorter than for the other copyrightable works" [23] (p. 19). This is an important thing to be remarked, since non-authored works may enter the public domain much earlier than authored ones. Madeleine de Cock Buning made an interesting reflection on this: "Without any form of intellectual property protection, these works can be used, reproduced, changed and distributed to the benefit of all. One can argue in favor of this option where Artificial Intelligence Systems creation is a positive consequence of Artificial Intelligence to the benefit of society as a whole" [8].

This also avoids also the application of moral rights, especially important in Civil Law, authors' right countries, but not so much in Common Law countries: in the United Kingdom, for instance, journalists are an exception of moral rights and the companies have no obligation to mention the name of their hired workers-although they usually recognize them as authors, all the way. This legal provision, and the similar one planned in Australia in the Final Report on the Digital Platforms Inquiry by 
the Australian Competition and Consumer Commission (ACCC), published on 26 July 2019, states the importance of enacting such a right for press publishers, to help them monetize content.

The question of authorship, which is an unwaivable moral right in many countries, most especially in Civil Law ones, is of crucial importance when examining the changes that artificial intelligence systems-aided news production can cause to journalists and companies. In many Civil Law countries, authorship is only applicable to human creators, not to corporate entities or to software. Also, in the United States, even if such provision does not appear in the Copyright Act, we can consider that there is a similar principle, since the Copyright Office has repeatedly declared that it will "register an original work of authorship, provided that the work was created by a human being". In the gathering phase of the journalistic work, artificial intelligence systems act as a simple tool-no matter how complex is their design, they are manipulated by human people - and produce no final work to be published. Facts and data, it should be remembered, are not protectable by themselves. We agree with Lin Weeks: "At the highest level of abstraction, automated journalism stories consist of an algorithm, or input (known in the industry as clean data), and of prose output" [19] (p. 85). Copyright law can only protect the second.

Copyright law only covers the final output placed into public knowledge using intellectual skills. Moreover, human authorship is to be recognized when artificial intelligence systems are used for data gathering, text mining, searches or verification. Since the initial work to be improved is made by human people, the final result is also due to them, and not to machines. When AIS is used for content curation as well, as a starting point for news items creation, the final authorship is of human journalists. A similar case happens when a journalist or editor revises the mistakes made by artificial intelligence systems. The final responsibility before the final publication of work is due to an individual or to the corporate entity, in any case.

It is obvious that the development of software can be authored by someone and commissioned by a company, which is the usual case. Following Lin Weeks, the protection of the algorithm itself, considered, we should add, as a form of software, is uncontroversial; more problematic is how to protect the output itself [19]. Whenever software is an instrument for creation, the final responsibility of the output is due to human authors. It is unusual, but not impossible, that just one individual is the inventor of the AIS software and the creator of the work. At least, there is one early example of it, the aforementioned Ken Schwencke, a journalist who both programmed an algorithm and exploited the results of it in 2014. Since he controlled the whole process, he signed the news. There is some way to attribute authorship to the programmer in countries such as Hong Kong, the United Kingdom, Ireland, India or New Zealand, all of the Common Law countries. For instance, section 9(3) of the Copyright, Designs and Patents Act (CDPA) states that "in the case of a literary, dramatic, musical or artistic work which is computer-generated, the author shall be taken to be the person by whom the arrangements necessary for the creation of the work are undertaken", but it adds in section 178 that to be considered as that, it must be "generated by computer in circumstances such that there is no human author of the work" There is a parallel comparison, for instance, with generative music. A musician can use software (one example is Wotja, developed after the suggestion of musicians such as Brian Eno) to create music adjusting some parameters and patterns, and once done that, the artificial intelligence system starts creating music, which in turn can be modified whilst playing. The authorship of such musical pieces is of those human beings who decide which parameters must be adjusted, when and how. We agree with Andrés Guadamuz when he said that "the idea behind such a provision [referring to the UK Copyright Act] is to create an exception to all human authorship requirements by recognizing the work that goes into creating a program capable of generating works, even if the creative spark is undertaken by the machine" [24].

When the creation of a work is only the result of artificial intelligence systems, with no human intervention at all, which is thought to be only possible in randomly created outputs, this may be possible in music but hardly in news reporting, since it may result in a lack of sense. Anyway, there are some cases, for instance the Australian Acohs Pty Ltd v Ucorp Pty Ltd, which declare that a work 
not produced by a human cannot be protected by copyright (Gadamez, 2017). Some other cases, for instance in the European jurisdiction, insist in the decisive intervention of human beings in the final result for a work to be considered copyrightable: the Court of Justice of the European Union delat with that question in C-145/10, Eva-Maria Painer/Standard Verlags [2011], C-604/10 Football Dataco/Yahoo! [2012] [9] (p. 321).

The main point is, then, originality, and how to define it. In the mentioned European cases, it is required that the work is "the author's own intellectual creation", so in some way it must be (concurrently with a Civil Law, authors' right legal tradition) an oeuvre de l'esprit: some personal touch must be found in the work. Even if artificial intelligence systems can show some creativity, meaning that they can generate works using data, patterns and algorithms, it is far more difficult to find some originality in them. Once again, the CJUE has insisted on this point, e.g., in C-5/08 Infopaq International $A / S$ v Danske Dagblades Forening, declaring that it is essential to find some elements of personality in a work to be protected under copyright law. Whenever a human intervention is a sine qua non condition to produce the work, such a personality characteristic can be detected. Human intervention is always needed: software cannot create software, so, according to the World Intellectual Property Organization (WIPO), there are only two ways to face this problem: to deny copyright protection to works created exclusively by computers or to attribute it to the creator of the program. There is a third way in the case of news: to attribute it to the corporate entity responsible for the collective work in which this artificial intelligence systems-aided work is inserted. In this case, and the Resolution of the 2019 AIPPI World Congress con Copyright in artificially generated works insists on it, a related, neighboring, ancillary or sui generis right is needed for publishers.

To our knowledge, this has not happened yet, but it is not impossible to think that artificial intelligence systems-aided news, which may use third parties' data, could infringe copyright whenever the origin and eventually author of the original works from which the derivative one is developed are not properly mentioned, and the corporate person who publishes it could be sued for it. Such a case will help to clarify positions, and it has been mentioned, but not developed, in the Resolution adopted in September 2019 by the AIPPI World Congress. It is not impossible, we should add, that in some cases such practices could be considered under quotation exception-or fair use in the Common Law countries-but anyway it must be examined case by case, with no need to create new exceptions [23] (p. 11), especially in legal areas such as the European Union, in which a closed list of exceptions has to be applied. Obviously, in countries where fair use or fair dealing is applied, a case-by-case approach will be needed.

Another interesting point of view is how the media manage artificial intelligence systems to automatically display some kind of information, a question that has been examined by Jop Esneijer: "Note that automated scanning of tweets and blogs for relevant content and copy or even publishing them [...] would in principle also require the authorization of the original author as these are acts of copying or making available to the public, unless they are excepted, for example because they fall under" [25] (p. 43). This is because we are dealing with derivative works.

It is different when news items are mainly created with the aid of artificial intelligence systems, in which case the attribution of paternity is shown as anonymous or attributed to the corporate person. This is consistent, as we have already mentioned, with that old distinction of the Berne Convention on Copyright of 1886-1887, which in Article 2 stated that the consideration of "literary and artistic works "shall not apply to news of the day or to miscellaneous facts having the character of mere items of press information". The Berlin Convention of 1908 defined to a greater extent which works amongst the ones published in a newspaper were copyrightable or not, the ones that could be reproduced-always mentioning author and origin—or not. The Berlin Convention protected any work published in a newspaper, which was a great advance compared with the previous conventions, which distinguished between literary works and nouvelles du jour. In fact, the distinction was maintained in the following conventions, those of Rome (1928), Brussels (1948) and Paris (1971; amended in 1979), now in Article 2.8. This old distinction can now have a new fashion regarding the production of news 
items produced exclusively or mainly by artificial intelligence systems or produced under the final responsibility of human authors, but the rights on the economic exploitation of all of them are, anyway, to be recognized to copyright holders of the collective work. Some scholars have examined these cases, and concluded that the common practice is for the corporate entities to sign those news items using the company's name, and scarcely mentioning the fact that they have been generated with artificial intelligence systems' aid [21] (p. 13).

\section{Discussion}

Innovation in journalism, specially from the advent of the World Wide Web in the mid-1990s, is a central point for companies and researchers. The media industry is facing a major crisis, most especially from 2008 onwards, in which companies are trying to redefine a successful business model, searching for a viability for an activity to that point sustained mainly by advertisement. Optimizing all economic resources is thus crucial for this industry, as some many scholars have insisted, and in this respect automated tools may be "the key to the viability of news media in the digital age" [26]. It is in this context that we must situate the discussion on the role of intellectual property law when applied to the outputs of automated journalism. Companies need to monetize content, and developing artificial intelligence systems to help journalistic work for gathering data, elaborating news and disseminating them-even to commercialize them more efficiently—can help in this purpose. In most cases, as we have examined, artificial intelligence systems need human intervention at some point and this leaves some personality clue which leads to considering the output a characteristic of originality, needed for copyright law to be applied. Investment should, on the other hand, be enhanced. The most developed proposal to this point, the Resolution of the 2019 AIPPI World Congress con Copyright in artificially generated works, after consultation with many national groups all over the world, concludes that the majority of them "consider that the investor (natural or legal person) should be the original owner of the artificially-generated works [23] (p. 16)."

New profiles are appearing in news reporting: journalists incorporate new skills to traditional ones, and one of them, regarding to automated news, is to be a designer, programmer, supervisor or editor of news items created with the help of software [12] (p. 284), so adaptation of skills and training seems more necessary than ever [27].

The legal recognition of the journalist as an author, laboriously developed through history, is jeopardized once again. An individual approach to intellectual property (ultimately, an authors' rights approach) is more difficult to defend and the central role in copyright law is now that of the collective, and even of the derivative work. In the more optimistic views, this is good news for journalists, since artificial intelligence systems-aided production may free human journalists from heavy tasks and reserve them for an extra level of coverage [21] (p. 5,6) (reports and features, basically) with a more added value and, following the old Berne Convention literal, a more "literary" approach. Anyway, there are some ways to alternatively attribute authorship, or related rights, to a natural person or a corporate entity, and in every case AIS-aided news should be attribute to someone. Preserving the notion of authorship is extremely important in this regard. It is probably more difficult to preserve moral rights when the weight of the tasks to produce a news item is shared between software and a journalist, and in some way that weight should be balanced, but regarding economic rights we agree with the conclusions of Osha et al, 2019, that they "should not differ between artificially-generated works and regular works" [23] (p. 10). It is quite difficult, anyway, to attribute moral rights to the inventors of designers of artificial intelligence systems, and it is even difficult to attribute them to journalists who help produce artificial intelligence systems-aided news in countries like the United Kingdom, for the aforementioned reasons: Article 79 of the Copyright, Designs and Patents Act, 1988, states that the moral right "does not apply to a computer program [ ... ] any computer generated work" or "in relation to the publication in a newspaper, magazine or similar periodical". Even if it may seem a quite restrictive provision, it provides a clue about how things can be held regarding to the specific topic of this paper. 
To this extent, it seems that there is a general agreement that, following the definition of the Resolution of the 2019 AIPPI World Congress con Copyright in artificially generated works, "AI generated works should only be eligible for protection by Copyright if there is human intervention in the creation of the work and provided that the other conditions for protection are met. AI generated works should not be protected by Copyright without human intervention". The extreme case is when artificial intelligence systems (AIS) are able to learn for themselves and create news autonomously, in which case the so-called "creative agents" are machines [9], or, using the title of a symposium held in Alicante (Spain) on the topic in 2019 [28], whether it might happen that robots can invent and create. As we have examined before, this is not the most usual situation in media, and when it happens the output is usually mere news, as stated in the Berne Convention on copyright, not attributable to any author, but of economic interest for corporate entities as part of a collective work. This appears to be the main category in these times, in which, trying to combat a structural crisis, the media industry is aiming to defend its interests by enforcing this legal category. Another example is how the major newspaper industry in Europe has managed to include a new ancillary, exclusive exploitation right in the European Union's Directive on Copyright of 2019, the so-called press publishers' rights. Even though in Article 17 of the Directive automated news is not mentioned, this literal could be eventually used to defend the media's economic interests, with no need to compensate any human author.

The general trend should be, in our opinion, to concede that there is some originality whenever some human intervention is required at some step of the journalist routine, and some guidance, pattern providing, instruction, deep revision of news items is provided before publication. Personal authorship should not be conceived as a romantic conception of the sole creation of a work due to an individual inspiration, but to any intellectual skill required to place in the market a work to be properly and coherently understood by human people. Even in some more unclear cases, the responsibility of the corporate entity in the production and insertion of such a product in a collective work should be a sufficient condition to secure a neighboring, ancillary right or even a sui generis right generated by the responsibility in providing instructions to structure databases (not such other things are digital media in these days) and design interfaces to exploit them [23] (p. 7). A balance between the rights of the investors, the inventors and the workers is needed, as they are the rights of the audience and public knowledge. In this sense, a revision of the duration of rights is needed, and much shorter rights are foreseen to help enter artificial intelligence systems-aided news into the public domain.

Funding: This research was funded by the Ministry of Science and Innovation of Spain, grant number RTI2018-095775-B-C43 (Project: News, Networks and users in the hybrid media system. Transformation of the media industry and the news in the post-industrial era).

Conflicts of Interest: The authors declare no conflict of interest.

\section{References}

1. Diakopoulos, N. Algorithmic accountability. Algorithmic accountability. Journalistic investigation of computational power structures. Digit. Journal. 2015, 3, 398-415. [CrossRef]

2. Dörr, K. Mapping the field of algorithmic journalism. Digit. Journal. 2016, 4, 700-722. [CrossRef]

3. Diakopoulos, N. Automating the News. How Algorithms are Rewriting the Media; Harvard University Press: Cambridge, MA, USA, 2019.

4. Marconi, F. Newsmakers: Artificial Intelligence and the Future of Journalism; Columbia University Press: New York, NY, USA, 2020.

5. Hansen, M.; Roca Sales, M.; Keegan, J.M.; King, G. Artificial Untelligence: Practice and Implications for Journalism; Tow Center for Digit. Journal, Columbia University Libraries: New York, NY, USA, 2017.

6. Ford, M. Could artificial intelligence create an unemployment crisis? Commun. ACM 2013, 56, 37-39. [CrossRef]

7. Graefe, A. Guide to Automated Journalism; Columbia Journalism School, Tow Center for Journalism: New York, NY, USA, 2016. Available online: https://pdfs.semanticscholar.org/c56d/609b3cb2ff85a3e657d2614a6de45ad2d583.pdf (accessed on 7 May 2020). 
8. De Cock Buning, M. Autonomous Intelligent Systems as Creative Agents under the EU framework for Intellectual Property. EJRR 2. Spec. Issue Man Mach. 2016, 7, 310-322. [CrossRef]

9. Newman, R. Journalism, Media, and Technology Trends and Predictions; Reuters Institute for the Study of Journalism: Oxford, UK, 2018.

10. Díaz-Noci, J. Authors' rights and the media. In Interaction in Digital New Media; Pérez-Montoro, M., Ed.; Palgrave: Gram, Switzerland, 2018; pp. 147-173.

11. Díaz-Noci, J. Copyright and User-Generated Contents for Mobile Devices: News, Entertainment, and Multimedia. In Between the Public and Private in Mobile Communication; Serrano, A., Ed.; Routledge: London, UK, 2017; pp. 199-217.

12. Segarra-Saavedra, J.; Cristòfol, F.J.; Martínez-Sala, A.M. Inteligencia artificial (IA) aplicada a la documentación informativa y redacción periodística deportiva. El caso de BeSoccer. Doxa Comunicación 2019, 29, 275-286. [CrossRef]

13. Becket, C. New Powers, New Responsibilities. A Global Survey of Journalism and Artificial Intelligence; London School of Economics: London, UK, 2019.

14. Leone, R. The Mashup Man. An Online Innovator Uses an Ingenious Fusion of Imagery and Databases to Present Information in Exciting New Ways. Am. Journal. Rev. 2007, 28, 10-14. Available online: http://ajrarchive.org/Article.asp?id=4258 (accessed on 25 March 2020).

15. Kelley, M. Web 2.0 Mashups and Niche Aggregators; O'Reilly: Sebastopol, CA, USA, 2018.

16. Boyles, J.L.; Meisinger, J. Automation and Adaptation: Reshaping journalistic labor in the newsroom library. Converg. Int. J. Res. New Media Technol. 2020, 26, 178-192. [CrossRef]

17. Fletcher, R.; Schifferes, S.; Thurman, N. Building the 'Truthmeter': Training algorithms to help journalists assess the credibility of social media sources. Converg. Int. J. Res. New Media Technol. 2020, 26, 19-34. [CrossRef]

18. Stern, R. FL\#195: A home page designed by algorithm. Reynolds Journal. Inst. 2017, 24. Available online: https://www.rjionline.org/stories/fl195-a-homepage-designed-by-algorithm (accessed on 20 March 2020).

19. Weeks, L. Media Law and Copyright Implications of Automated Journalism. J. Intellect. Prop. Entertain. Law 2014, 4, 67-94.

20. Belz, A. Fully Automatic Journalism: We Need to Talk About Nonfake News Generation. In Proceedings of the Conference for truth and trust online-BMA House, London, UK, 4-5 October 2019.

21. Ufarte-Ruiz, M.J.; Manfredi, J.L. Algorithms and bots applied to journalism. The case of Narrativa Inteligencia Artificial: Structure, production and informative quality. Doxa Comunicación 2019, 29, 213-233. [CrossRef]

22. Hugenholtz, B. Copyright Reconstructe: Rethinking Copyright's Economic Rights in a Time of Higly Dynamic Technological and Economic Change; Wolters Kluwer: Amsterdam, The Netherlands, 2018.

23. Osha, J.P.; Verschuur, A.M.; Laakkonen, A.; Guillaume, G.; Nack, R.; Shen, L. AIPPI. Copyright in Artificially Generated Works: Resolution; AIPPI World Congress: London, UK, 2019.

24. Guadamuz, A.; Artificial Intelligence and Copyright. WIPO Magazine. 2017. Available online: https: //www.wipo.int/wipo_magazine/en/2017/05/article_0003.html (accessed on 25 March 2020).

25. Esneijer, J.; Nieuwenhuis, O.; Mijs, C.; Versloot, C.; Helberger, N.; Van der Sloot, B.; McGonagle, T. Making User Created News Work; TNO 2012 R11277; IViR: Amsterdam, The Netherlands, 2012.

26. Pavlik, J. Innovation and the future of journalism. Digit. Journal. 2013, 1, 181-193. [CrossRef]

27. Small, J. NewsLab '20 Gathers Human Brainpower to Ponder Roles for AI in Journalism, Media Industry; Local Media Association: Lake City, MI, USA, 2020. Available online: https://www.localmedia.org/newslab-20-gathershuman-brainpower-to-ponder-roles-for-ai-in-journalism-media-industry/ (accessed on 25 March 2020).

28. Fernández-Lasquetty, J.; López-Tarruella, A. Summary of the Congress: Can Robots Invent and Create? A Dialogue between Artificial Intelligence and Intellectual Property; University of Alicante: Alicante, Spain, 2019.

(C) 2020 by the author. Licensee MDPI, Basel, Switzerland. This article is an open access article distributed under the terms and conditions of the Creative Commons Attribution (CC BY) license (http://creativecommons.org/licenses/by/4.0/). 